\title{
Model/Models in linguistics
}

\section{Wilfrid Rotgé}

\section{(2) OpenEdition}

\section{Journals}

Electronic version

URL: http://journals.openedition.org/asp/1574

DOI: $10.4000 / a s p .1574$

ISBN: 978-2-8218-0388-6

ISSN: 2108-6354

Publisher

Groupe d'étude et de recherche en anglais de spécialité

Printed version

Date of publication: 1 December 2002

Number of pages: 5-22

ISSN: 1246-8185

\section{Electronic reference}

Wilfrid Rotgé, «Model/Models in linguistics », ASp [Online], 35-36 | 2002, Online since 04 August 2010, connection on 10 December 2020. URL : http://journals.openedition.org/asp/1574 ; DOI : https:// doi.org/10.4000/asp. 1574

This text was automatically generated on 10 December 2020.

Tous droits réservés 


\title{
Model/Models in linguistics
}

\author{
Wilfrid Rotgé
}

1 When ${ }^{1}$ one looks up Model / Models in the indexes of linguistics books, one is struck by the relative paucity of occurrences of this word. Few linguists - especially enunciative and cognitive linguists - bother to list it in their books. Does that mean that the chapter has to be closed before we have even opened it? Does that mean that we have no other choice than to move on to something else, to resume business as usual, and go on, for example, with a study of the umpteenth theory on this vs. that or the uncanny use of the modal should in 19th century hypothetical subordinate clauses?

2 Not quite, were it only because I agreed to give a paper on Model / Models, and I'm still here and I'm a linguist. As a linguist, I will at times be using very technical words, especially in my third section entitled "Model / models in grammar: the phrase and the sentence". We are dealing with models here, so some abstract terminology is unavoidable. However, I'll do my best to define the less common words.

3 My contention is also that the notion of model is in fact central to linguistic inquiry, in spite of the paucity I have just mentioned. I'm going to present a list of linguistic areas in which models are used.

4 The notion Model / Models does not immediately conjure up anything specific in the mind of a linguist, especially if he or she has been trained in France, in the highly popular trend of linguistics called énonciation, which I will anglicize as "enunciation". In other words, this notion is not specifically linked to linguistics, and when a linguist is asked to define what a model is, several definitions, associations or meanings spring to mind.

5 That being said, any linguist familiar with Chomskyan and post-Chomskyan theories will instantly associate models with syntactic structures and sentence building. In generative grammar, the brain child of Noam Chomsky, a sentence is supposed to comply with a syntactic pattern, which is a model for sentence building.

6 I would first like to go back to basics to see what a model or models may be. I can immediately cross out one meaning that some morally-minded people might find the most disreputable. In Britain, streetwalkers are sometimes referred to as "models", 
especially in written advertisements (e.g. stickers found on telephone boxes). This euphemistic use of the word "models" is based on the other, more conventional meaning:

A model is a person, especially a young woman, employed to model clothes,

hairstyles, cosmetics, etc. (Longman Dictionary of English Language and Culture)

We clearly witness a metaphoric use here that can be related to fashion models' supposed mores or styles.

With the cosmetics and fashion industry we have a more honorable definition of "Model / Models" that I can make use of. A model in that industry is a person who wears clothes for a person other than herself or himself. A model is therefore a thing or a person that can be copied.

The etymology does not help us much in our exploration of models: "model" comes from the Latin modulus, which itself comes from modus, i.e., manner, measure and which is connected with the word "mode". We may just suggest that with a model there's a manner, a mode that is to be followed or copied.

Intimately connected with the notion of models is the idea of representation: something represents or stands for something else that is larger or that appears in larger numbers than the model. This idea of representation is central to some studies in linguistics as will be seen.

11 Another acceptation of the word model has to do with not just what can be copied but with what ought to be copied, with what is eminently "copiable". This is a judgmental use of the word as in "This linguistics book is a model of conciseness" or "Ms X is a model linguist". But I'm not here to mark my fellow linguists or their productions and shall therefore pass over this use of the word.

\section{Model / Models in applied linguistics}

In applied linguistics, however, this sense of a model as someone or something used as an exemplar is often encountered. Foreign language teaching implicitly requires a model, in that a specific dialect, usually the standard dialect, of a given language is very often used as the model. As English teachers, we have a model in mind, which will lead us to frown on utterances like:

[1] We c'n eat anyt'ing we wants [...] anyt'ing wot's good. (Henry Roth, Call It Sleep)

13 This utterance is pronounced by a character named Leo. Spell checks also follow an explicit model as my computer reminded me when I typed the two sentences borrowed from Call It Sleep. The model used by my computer did not like and therefore rejected in red c'n, anyt'ing and wot. Now the novelist when writing these sentences clearly had a linguistic model in mind, a model from which one of his characters departs systematically and in a systematic way, thus creating a new model but which is considered as substandard. Henry Roth's representation of an anti-model, that is his character's model, is not completely consistent, though. When he writes $c^{\prime} n$, he clearly wants to show that this is not in keeping with the model he uses as a writer, but at the same time there is nothing wrong with saying $c^{\prime} n$ in an utterance: can should be pronounced $c^{\prime} n$ in this context. What is flawed is the spelling, but not the pronunciation and as it is a dialogue, the character 
himself is not mishandling the English language, despite what the novelist would like us to believe.

The same goes for wot, a misspelling of what. But the word what is pronounced as ' $w$ ' ' $\mathrm{o}$ ' ' $t$ '. So, the phonetic model is quite standard; again it is the written representation that is flawed. In anyt'ing, which is meant to be pronounced anyting, the spelling clearly indicates departure form the standard model of the English language.

What my computer did not object to was the syntax used by the character in the phrase we wants or the use of wot / what as a relative pronoun connecting an antecedent (anyt'ing) and the rest of a relative clause (is good). Our unavoidable and necessary representation of a model as speakers of the English language cannot but bring about some reaction when reading these words, be it of approval, disapproval, mockery, sympathy or whatever. Be that as it may, the character's words in the quotation do not conform to the model, called standard, of the English language.

So, there is a model in applied linguistics which relies on the model used by most grammarians, lexicographers and so-called careful speakers of the language, such as can be heard in news coverage on television and the radio. The model may vary, depending on the variety used (British or American or any other), but it is there.

Contemporary grammarians tend not to be prescriptive when describing a given language, but any description is bound to include recommendations like "Do not use... / Use..." even if the prescription is presented somewhat less forcefully, as in this quotation from Practical English Usage, by Michael Swan:

Inversion is not used after non-emphatic adverbial expressions of place or time [...] NOT Not far from here can you see foxes. Inversion is used when not + object is put at the beginning of a sentence for emphasis. Not a single word did she say. (1995: 299)

8 The passive phrase in this quotation (is not used) is less prescriptive than the imperative ( Do not use), but only just.

There is now a politically correct way of saying Do not use... The gradations between formal / standard / informal / non-standard / vulgar in grammar books or dictionaries are PC ways of recommending, if not prescribing, a specific form or construction. They certainly remain an appeal to conform to a model.

This appeal is of course looser than in the old days, when injunctions like Say this / Do not say this were much more common, accepted and expected, as in this quotation from a French book of English grammar published in 1779:

Le prétérit composé français, j’ai aimé, s'appelle passé indéfini, parce que l'espace de tems marqué par ce prétérit n'est jamais entièrement écoulé. En conséquence, on dit, j'ai fait telle chose aujourd'hui, ce matin, ces jours-ci, cette semaine, ce mois, cette année, \&c. autre précision qui manque dans l'anglois. Car dès qu'on y nomme un tems passé, n'y eût-il qu'un instant de distance du présent, on se sert du prétérit simple. (Miège et Boyer 1779: 128)

Grammars these days shy away from using phrases like On dit. Dictionaries follow models, too, lexical models, that is. A well-known bilingual dictionary (Robert \& Collins) uses special marks "to provide a warning to the non-native speaker":

One asterisk in this dictionary after a word "indicates that the expression, while not forming part of standard language, is used by all educated speakers in a relaxed situation but would not be used in a formal essay or letter, or on an occasion when the speaker wishes to impress." 
Two asterisks "[indicate] that the expression is used by some but not all educated speakers in a very relaxed situation. Such words should be handled with extreme care by the non-native speaker unless he is very fluent in the language and is very sure of his company."

Three asterisks "[mean] 'Danger'! Such words are either 'swear words' or highly indecent or offensive expressions which should be avoided by the non-native speaker."

- etc.

$$
\begin{aligned}
& \text { I like it -> I don't like it } \\
& \text { Paul hates Mary } \rightarrow \text { Paul doesn't hate Mary }
\end{aligned}
$$

The model was a syntactic structure that had to be copied. This model completely disregards meaning / semantics and was opposed by communicative grammar.

A model can also be conceived as a set of rules that allow speakers to make themselves understood. If ebonics or what used to be called Black English, for instance, is not viewed as an exemplar by many Americans, it can clearly be described according to a set of rules that make up a model. The street English used in the novel Call It Sleep also follows an abstract model taken up by each one of its speakers.

[2] 'Even if yuh wears 'em [rosaries], dey bring yuh luck. When me ol' lady had her appendixitis cut out, she has one o' dem under her piller ev'y night, an' dat's w'y she got better [...] an' ev'y time I goes swimmin' in de Hudson I always cross meself t'ree times - like dat. Den yuh kin Johny-highdive all yuh wants an' yuh'll hit bottom - didn'tcha know dat? [...] Doncha know de Woigin Mary w'en yuh sees her?'

We have a consistent use of a model of English here, with the following rules:

- the voiced dental fricative, or voiced th- sound, is pronounced as a /d/ or elided

- elision of /d/ at the end of a word: ol'; an'

- -s inflection for 1st person singular and second person

- $/ \mathrm{j} /$ replaced by a postalveolar fricative phoneme after $/ \mathrm{t} /:<\mathrm{tcha}>$

- <ir $>$ / <or $>$ / <er> pronounced /oi/

- $<$ wh $>$ pronounced /w/ and not /hw/ in standard American

So, we are left with two definitions of a linguistic model: a model conceived as an exemplar (this is the model implicitly recommended by grammar books, dictionaries and spell checks) and a model viewed as a set of rules that are reproduced by speakers of a given variety of a language.

As linguists, we are expected to take into account all varieties of a given language. We are not supposed to be judgmental, to say that one model is better than any other. This is the role of the institutions that govern us. The problem is that we are part of these institutions and as teachers we are required to teach an exemplar. In other words, if we 
were to mark Leo's English (the character in the novel Call It Sleep), we would not give him full marks. Even though he complies with his model consistently, he does not comply with the standard model.

As teachers, we are constantly faced with questions like 'Should I accept the phrase Like I said?' I may have an explanation for the use of the -s ending in Like I says but that does not mean that, however consistent and explainable this use may be, I'll let it pass. The question raised at this stage is 'How strict a linguistic model should we have as teachers of the English language?'. For the time being, the answer does not rest with us but with rapports de concours.

Before I started talking about models as exemplars, I gave the following definition of a model: "A model is a thing or a person that can be copied". I also said that models were connected with the idea of representation. The question raised now is: what can be copied in linguistics? To what field or aspect of linguistics can the concept in question be applied? One area that relies heavily on models is phonetics.

\section{Model / Models in phonetics}

The phonologist builds models of the organization of the speech continuum by using such contrasts as phonemes. Some phonologists talk about "the phonemic model of analysis", that is, phonemes constitute a model with a limited set of elements that can analyze all speech productions. With phonemes, we can devise a model to represent the indefinitely large range of sounds heard in languages (Cobley 2001).

What is important for our discussion is to remember that phonemes are abstract units. They represent sounds in an abstract way; they are not meant to echo sounds directly. A well-known example of the abstractness of phonemes is provided by $/ 1 /$, whose realization depends on the context in which it appears: it may be realized as 'clear' (as in late) or 'dark' (as in milk).

Incidentally, a phonemic transcription of the word milk should be $/ \mathrm{milk} /$, without a crossed / $1 /$, in that a crossed $/ 1 /$ is considered as a variant of the phoneme / $/$ and not as a phoneme as such. Indeed, two words cannot be distinguished on the basis of the difference between a clear /1/ and a dark /1/. All the more so as in Scotland / $/$ tends to be dark in all its occurrences whereas in southern Ireland many speakers only use a clear /l/ (See Durand 2001).

34 The number of phonetic realizations differs according to the phoneme in question. The phonetic realizations are called allophones. There are at least seven allophones of the phoneme $/ t /$. But the phoneme $/ t /$ provides a model for all its allophones. The various allophones are very often the result of assimilation, that is, the tendency of a sound to move to the place of articulation of the one following (Cobley). We thus see that a phonemic transcription of a string of words provides a model for the various phonetic realizations of those words. The "phonemic model of analysis" is still under scrutiny and not everyone agrees with the phonemic model. Other models could be suggested. Be that as it may, the notion of model is central to phonetics.

The other acceptation of the word "model" (something or somebody used as an exemplar) is also central to phonetics. I can quote Roach and Hartmann (1997):

A pronouncing dictionary must base its recommendations on one or more models.

A pronunciation model is a carefully chosen and defined accent of a language. 
ther model is called Public School Pronunciation (now that's very dated) or Received Pronunciation or BBC English or British English is not relevant for the current discussion.

\section{Model / Models in grammar. the phrase and the sentence}

Models can be found in grammatical studies and in one area in particular: many linguists have been or are concerned with devising a model for the production of sentences. There are other linguistic areas in which models can be found. I'll concentrate mainly on models for sentences. For this purpose, I'd like to examine in detail models provided for the description of sentence production. One name stands out in that field, that is, Noam Chomsky. He is the initiator of what is called the transformational-generative theory.

Several versions or stages of this theory exist, so cut a long theory short, I'll briefly present one stage, that is, one model of the theory (the word model is actually used extensively by proponents of this approach).

The model presented here is currently the most popular and best known approach worldwide to syntactic analysis. We have to face the fact that French linguistic theories are not known outside French-speaking countries, despite a few translations of enunciative linguists in a few university presses. This cannot be ignored. Nor can non-enunciative theories be ignored or, worse, despised, as is often the case.

The underlying idea of syntactic analysis is that a sentence is not formed by stringing words together like beads on a necklace. The hierarchical pattern of sentence structure has to be accounted for.

\subsection{Model / Models for phrases}

A sentence can be divided into a number of phrases, as in the following model:

\begin{tabular}{|c|c|}
\hline $\mathrm{NP}_{-}$(Det) N (PP) & [NP = Noun Phrase $]$ \\
\hline VP _ (Qual) V (NP) & [VP = Verb Phrase] \\
\hline $\mathrm{AP}_{-}$(Deg) A (PP) & [AP = Adjective Phrase $]$ \\
\hline $\mathrm{PP}_{-}$(Deg) $\mathrm{P}(\mathrm{NP})$ & {$[\mathrm{PP}=$ Prepositional phrase $]$} \\
\hline
\end{tabular}

41 This set of rules is explicitly presented as a model by generative linguists. The first rule states that the noun phrase can consist of a determiner, which is optional + a noun, i.e., the head of the NP, which is compulsory and a prepositional phrase which is optional too. In the second rule, 'Qual' stands for qualifier and in the third 'Deg' stands for degree word, both being what are traditionally called adverbs.

AP, the adjective phrase, in rule 3, can be composed of the following elements: highly dependent on his family: highly is a degree word (or Deg); dependent is the adjective and on his family the prepositional phrase (or PP). 


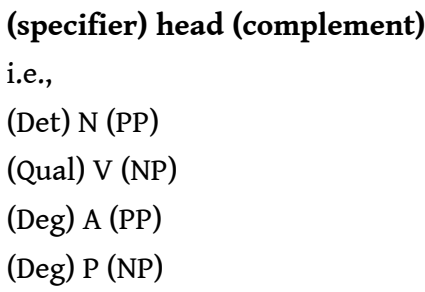

According to this model, the specifier can correspond to a Determiner, a Qualifier or a Degree word. This model can be summarized in turn by a more mathematical one, which provides a template for all phrases:

$$
\text { XP _ (specifier) X (complement) }
$$

In this template, X stands for Noun, Verb, Adjective or Preposition. A template is "a thin board or plate cut into a special shape or pattern, used as a guide for cutting metal, wood, clay, etc." (Longman Dictionary). We could specify "used as a guide or a model for cutting...".

This definition echoes the definition of a model given at the beginning of this paper: "A model is a thing or a person that can be copied." In the same way, a linguistic template proposes a pattern that can be reproduced. I'd like to add that the X notation is very popular in contemporary syntactic analysis and can therefore not be ignored by linguists, were it only to question it. This presentation can be somewhat refined with the so-called "X' notation" (or X-bar notation), which I'll explain later.

The problem with the previous rule, i.e., XP _ (specifier) X (complement), is that it does not show any hierarchy between the three elements, the specifier, the head and the complement. Now, the head and the complement should be attached together (they belong to the same level of phrase structure) and dissociated from the specifier. Hence this new refined model:

$$
\begin{aligned}
& X P_{-} \text {(specifier) X' } \\
& X^{\prime} X_{-} \text {(complement) }
\end{aligned}
$$

The first rule, XP _ (specifier) X', states that any phrase can consist of a specifier and an element, called X' (or X-bar). According to the second rule, $\mathrm{X}^{\prime}$ in turn consists of a head and its optional complement.

More precisely, the $X^{\prime}$ element can correspond to an $N^{\prime}$ (i.e., noun + complement [complement = a PP]), a V' (i.e., a verb + complement [an NP]), an A' (i.e., an adjective + complement [a PP]) or a P' (i.e., a preposition + complement [a NP]).

Modifiers, that is, adjectives and semantically loaded adverbs like slowly or timidly, can be added to the model, as in the following rule:

ASp, 35-36 | 2002 


\section{$\mathrm{XP}_{-}$(specifier) (modifier) X}

53 We are thus left with a pretty convincing model for phrases: all phrases conform to a three-item model: a specifier and an X', the X' being a head + its complement. However, this model is far from perfect. For instance, the notion of complement in this model is debatable, in that the complement in a Noun Phrase is far more optional than that of a Prepositional Phrase. In the phrase:

[3] The man in the moon

the PP in the moon is syntactically more optional than the NP on the bank in

[4] Don't rely on the bank lending you more money.

*Don't rely lending you more money.

And yet both are deemed to be complements and therefore equally optional. That being said, I agree that there is the basis for a viable model for phrases, for phrase structure.

Phrases combine to form a sentence. Now, can linguists devise a model for sentence building? Again, it is mainly with generative grammarians that a possible model can be found, though with many other grammarians, who do not explicitly raise the issue of a model for sentences, an implicit model can be traced, as will be seen. The concept of a model for sentences is more debatable.

\subsection{Model / Models for the sentence}

Traditionally and in a very simple way, a sentence can be analyzed as follows:

$$
S \rightarrow N P V P
$$

That is, quite simply, a sentence consists of a noun phrase and a verb phrase. This model is highly basic and requires refinement, too.

This generative grammar-inspired model can be improved by adding brackets to the first component:

$$
\mathrm{S} \rightarrow(\mathrm{NP}) \mathrm{VP}
$$

which means that the NP is optional in a sentence, as with imperatives or ellipted sentences.

Even then, the model provided does not take us very far. It might be universal, in that, most languages have verbs, so that it can be assumed that virtually all languages conform to the $\mathrm{S} \rightarrow(\mathrm{NP})$ VP rule or model. So that virtually every sentence pronounced in the world follows that model. This is quite impressive but at the same time the model is so general that its relevance is rather limited.

Some generative grammarians claim that this model sets the sentence apart, in that it differs too much from the analysis provided for phrases. They claim that the sentence should be treated like any other phrase, with a specifier, a head and a complement, as in the model presented above, i.e., (specifier) head (complement). In other words, a sentence is essentially similar to other phrases. Hence this new model for sentences: 


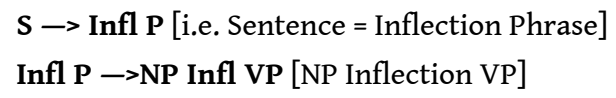
follow the specifier / head / complement pattern or model. How can this work? Simply by saying that a Noun Phrase is a Specifier, an Inflection is a head and a Verb Phrase is a Complement.

$$
\begin{aligned}
& \text { NP = Specifier } \\
& \text { Tense }=\text { Head } \\
& \text { VP = Complement }
\end{aligned}
$$

or:

$$
\text { Specifier / Inflection / Complement }
$$$$
\text { Noun Phrase / Tense / Verb Phrase }
$$

In turn, this diagram can be re-interpreted with the X' model I described earlier: a sentence can be conceived as something like the "(specifier) X (complement)" template. So, if we follow generative grammar, we have a similar template or model for both phrases and sentences, i.e., "(specifier) X (complement)".

$$
\text { [6] John loves Mary. }
$$

This sentence can be analysed as:

I' $\rightarrow$ I + SV [I stands for Inflection]

$I \rightarrow$ tense (present)

$\mathrm{SV} \rightarrow$ Specifier $+\mathrm{V}^{\prime}$

Specifier $\rightarrow$ John

V' $\rightarrow \mathrm{V}+\mathrm{NPV}$ 
$\mathrm{V} \rightarrow$ love

$\mathrm{NP} \rightarrow \mathrm{Mary}$

70 All this looks very neat and enticing, in that we would have the same model for each part of the sentence and for the sentence as a whole, which reminds us of the theory of fractals used in mathematics and literary criticism, but we'll see that it raises many questions.

Let's consider again the model for sentences provided above:

Noun Phrase = specifier $/$ tense or head $=$ Infl $/$ VP = complement same theoretical framework, determiners and qualifiers are also labelled as specifiers. Drawing a parallel between Noun Phrases and determiners is highly debatable, to say the least. In other words, a Noun Phrase is not a specifier in the same way that a determiner or a qualifier is.

The Noun Phrase pertains to the lexicon far more than the determiner or the qualifier which can be called "grammatical words" as they play a heavier part in the syntax of the phrase and in referential processes than in its meaning.

Also, how can a Noun Phrase be a mere specifier, when one knows its importance in the building of the sentence. It is a starting-point in the sentence, which means that it is more than just an element used to specify something relative to the meaning of a head.

In John loves Mary [6], John is essential and not a mere specifier. To me, the predicate loves Mary provides a comment upon John, the starting-point of the sentence.

Also, in this model, the Verb Phrase, love Mary, is considered as a complement. More precisely, it is the complement of the category called Inflection, i.e., tense. This again is problematic. How can a verb be the complement of a tense? Only if "complement" does not mean complement in the usual acceptance of the term. What's more, whereas complements are not compulsory, the verb is and it is therefore difficult to say that a verb is a complement.

Another debatable point is the fact that tense is presented as the pivotal element of a sentence.

To many linguists the head or the node of the sentence is simply the verb, or the verb with its subject, because a verb implies some sort of subject, which is therefore more than a specifier. This more traditional view of the sentence suits me better.

I'd like to add that I can see no reason why a sentence should follow the same pattern or template as a phrase. To use a trivial and imperfect comparison, if a wall is a collection of bricks, that does not turn a wall into a brick: the global structure of the wall is different from the structure of a single brick. In the same way, a set of phonemes is more than the mere addition of individual phonemes. In other words, /stri:t/ means more than just /s/ + $/ \mathrm{t} /+/ \mathrm{r} /+/ \mathrm{i}: /+/ \mathrm{t} /$.

That being said, whatever one may think of this model -and I have some reservations as I've just made clear- its strength lies in the desire to find basic rules that determine the architecture of a sentence, of any sentence in any given language. This desire pertains to universal grammar as conceived by generative linguists. Universal grammar provides all languages with the same general types of devices, like the phrase model or the sentence model (O' Grady et al. 1996: 234). 
81 As I said earlier, the model presented here is only one version within the framework of generative grammar, though it is one of the most popular. I'll spare the reader the other generative grammar-inspired models.

82 Another problem raised with the generative model for sentences is that the sentence is conceived as something autonomous, a self-contained system cut off from a real speaker. It is conceived as a disembodied construct, when cognitive research has illustrated that "grammar is an embodiment and a reflection of the way we both conceptualize the world around us and use the knowledge acquired to communicate with others of our species." (Heine 1997: 107).

In other words, a model for sentence building should take into account less abstract parameters, such as situational constraints and semantic relationships. Let's start with situational constraints.

\subsection{Situational constraints}

What is obvious and basic in the French approach to grammar, what is called "enunciative grammar", is completely ignored in the generative model, that is, the link between any utterance, any sentence and the situation in which the utterance is produced.

85 Any utterance requires as its basis and its bases three parameters, which I call basic shifters, i.e.,

\section{I / Here / Now.}

86 I / Here and Now are called shifters in that their meaning keeps shifting whenever a new speaker starts speaking. They are basic in that they provide the very basis of any utterance; they are obligatory components of any speech production, even though they are rarely explicitly mentioned in the sentence.

87 Any enunciative linguist acknowledges the existence and importance of these three shifters in any utterance, which implies that any model should have to take them into account. A more refined model would show that the shifter I is more central than Here and Now, in that Here and Now are dependent on the speaker (on I). The underlying Here and Now of any utterance are conceived relative to the I of the utterance. Hence this new model for the sentence:

$$
\text { I (here, now) }<\text { (sentence schema) }
$$

That is, the sentence schema is interpreted relative to the I (here, now) paradigm; it is dependent upon this paradigm.

The I / Here / Now trio has been made use of by French linguists for a very long time, by people like Damourette and Pichon, Guillaume or Benveniste among others. But the word "shifter" as applied to words like I / Here / Now was first used by Jakobson (1963).

\subsection{Semantic relations}

What about the sentence schema? Semantic relations exist within the sentence. They can be expressed in terms of forces, like source or origin and target or object, aim. Most 
sentences seem to include the expression of a source and that of a target. Added to this is a connector, prototypically embodied by a verb.

The order in English is most often of a "source / connector / target" type. Yet we all know that many languages follow a different pattern or alternate that pattern, like German, which uses either a "source / connector / target" pattern or "source / target / connector", or even "connector / source / target", depending on the status of the clause.

[7] Johann sah das Kind. (Source / Connector / Target)

Ich weiss, dass Johann das Kind sah. (Source / Target / Connector)

Dann sah Johann das Kind (Connector / Source / Target)

An overwhelming majority of languages place the source before the target in their basic word order, because the source corresponds to the topic, to what the sentence is about.

The connector or the verb always requires an explicit or implicit source, in other words it is not self-supporting, as it were, unlike a noun, which functions as its own support. If I say John, the name speaks for itself as it were, whereas if I say run, another word, a source, is required. Said differently, the verb is incidental to another word and the noun is incidental to itself. The subject of a sentence refers to the extralinguistic world of its own right as it were, in a way that the verb does not.

what are we left with in our search for a model for sentences? With not much unfortunately, or in any case with something extremely general. The following model may be suggested:

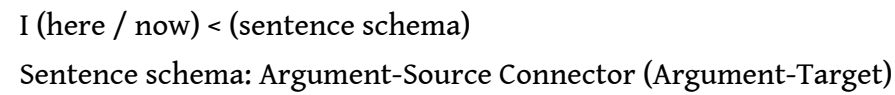

i.e., a sentence can be construed as a Source-Argument and a Connector, and the Connector may have as its second Argument a Target. And this in turn is constructed relative to an I / Here / Now pattern.

The sentence schema is not conceived as a triad (with a Source, a Connector and a Target) but as a complex dual system, with a Connector and its Source on the one hand, and a Connector and its Target on the other. The Source is the origin of the Connector + Target.

In this model, the verb is viewed, as is often the case, as a pivotal element; it provides the necessary link between the source and the target. The target is reached by the source through the medium of the verb.

However, this sentence schema does not mean that the Source will appear first in an utterance, before the Target. It does not mean either that the Connector will appear in medial position. In an utterance like [8]

[8] A good minister is what we need.

the Target appears in initial position. I can also mention [9] and [10]

[9] Here comes the bride.

[10] On the table lay a collection of Japanese scarves.

Or passive constructions in which the Source is most often not even mentioned.

This sentence schema raises a number of issues, though. Like the schema for intransitive verbs. In [11] 
[11] He woke up early this morning.

there is no second argument, the Target may be said to be included in the verb.

[11] or about in Dublin in [12]?

[12] I live in Dublin.

The sentence schema may be complemented as follows:

Source Connector (Target) (Here2 / Now2)

Here2 represents the place in which something takes place and Now2 its time. They can be called Here2 and Now2 to be differentiated from Here1 and Now1 (i.e., the here and now of the speaker).

I have presented here a simplifi ed model of the sentence on which many linguists would agree. It is necessarily extremely general and abstract. But that is precisely what models are for.

\section{Epistemology of the sentence model}

5 Now, the question one may ask oneself is why do generativists set great store by models, especially syntactic models and not enunciative grammarians? How come generative grammarians desperately want to devise a model for the sentence when enunciative grammarians are not particularly concerned with it? When one looks up an enunciative grammar book, few references are made to sentence models. Why is that?

6 Generative grammar is primarily concerned with universal grammar. That is to say, some generativists believe that each of us shares the same model for sentences, each human being stores the same model in his / her brain.

7 The model is made of rules that are part of what is conceived as "internal grammar" by Chomsky. These rules are supposed to apply to all languages and are used by some psycho-linguists (Roulin 1998: 344).

8 According to some generativists, there are a number of models, of universals stored in our brains and each individual language merely represents one state of the universal, innate propensity for language.

9 Among these universals, we find (Comrie 1989: 19):

- all languages have vowels;

- all languages have the following phonemes /p t k s i a u/;

- if a language has first/second person reflexives, then it has a third person reflexive.

Some universals are mere tendencies or "statistical universals" like:

- nearly all languages have nasal consonants;

- if a language has SOV basic order, it will probably have postpositions;

- in basic word order, the subject precedes the object (less than 1 percent of the world's languages violate this "statistical universal"), probably because of the salience of the agent in the agent-action-patient pattern; 
- languages in which the relative clause precedes the head noun are verb-final (i.e., if we have

"Relative clause + Noun", then we'll have the SOV pattern). course heavily influenced by linguistics, is interested in the existence of mental models, models that are supposed to exist in our minds. The concept of "mental model" was developed by the British psychologist Philip Johnson-Laird. To cut another long theory short, according to him, we build a mental model, that is, a representation of information as conveyed by the premise. When we hear a story like:

[13] The victim was killed in a cinema watching Bambi. The suspect was on a train when the murder was committed.

117 the first mental model that comes to mind is one that finds the sequence illogical, because the suspect cannot have been at the same time in the cinema and on a train, so the suspect is innocent. But another mental model can explain why the suspect is really a suspect: if the suspect was not in the cinema he or she can still have committed the crime in absentia, with poison or a professional killer. 
118 I do not intend to comment on mental models, as they fall outside the scope of my activities. I just wanted to mention them as they belong to linguistics and we're clearly dealing with models here. For further information, see Roulin (1998). More generally, story-telling is connected with models. Again, this is not in my sphere. I'll just mention the fact that attempts have been made to find narrative superstructures (see Denhière 1984), and therefore models for narratives. Black and Bower suggest that the reader's knowledge is organized in causal schemata (1980: 349) that make up a model for story understanding. All this is connected with logical deduction and representation in narratives.

Psycho-linguistic researchers often present their ideas of how language is processed in terms of models. These models very often take the form of charts made up of boxes and arrows. One such model is presented in figure 1.

Figure 1. Levelt's model of speech production

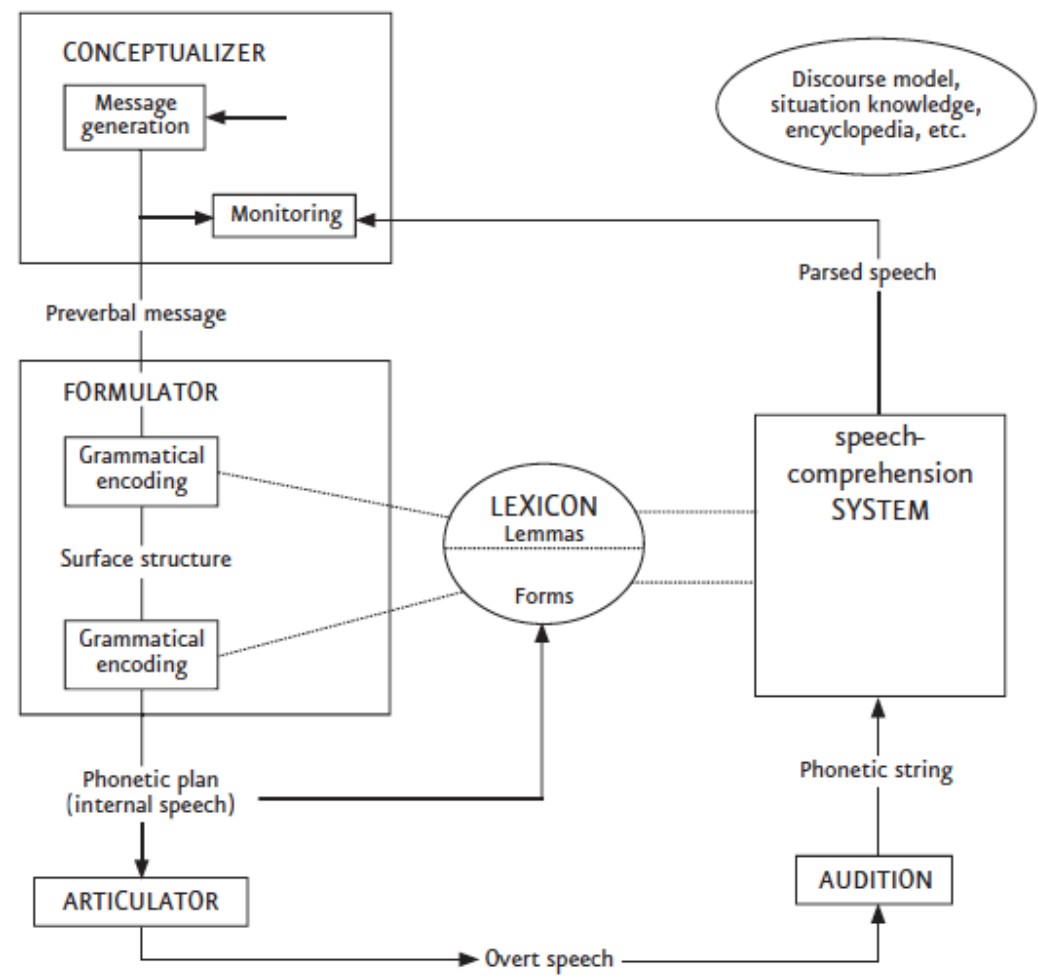

The diagram presented here is Levelt's model of speech production. It is considered as "the most influential model of speech production and is based on a wide array of psycholinguistic results" (O' Grady et al. 1996: 459). It states that speech production begins in the Conceptualizer (in which a message is formed). The message is then given linguistic form in the Formulator. This Formulator contains grammatical and phonological processes and draws upon the lexicon (represented in the centre of the model). From the Formulator, information is passed to the Articulator, which actually produces the utterance.

Information does not flow in one direction only. Rather there is feedback so that while producing language, a speaker monitors through the comprehension system whether the utterance makes sense. This is represented as an arrow that feeds back to the Conceptualizer. Although this model might look quite complex, it is a "great 
simplification" of what might actually occur in the mind during language processing (0' Grady et al. 1996: 459-460).

Again, this model is outside and beyond the scope of my activities as a grammarian. In devising such models, psycholinguists seek to discover the nature of the cognitive operations and computations that are employed when we understand and produce language. My aim is simply to present the "most influential model" used in psycholinguistics as it deals directly with our present concern, i.e., model / models in linguistics, but, as I have said before, this goes beyond my sphere as a linguist primarily interested in grammar and syntax.

\section{Conclusion}

A lot of scepticism has been expressed among linguists regarding models. Generativists have always had a weakness for them, but enunciative and cognitive linguists have always been wary of models for reasons that I have already mentioned. Both types of linguists reject the fact that language is self-contained and cognitively autonomous. They / we also refuse to set semantics and syntax apart. I can quote Langacker, a famous cognitive linguist:

...if semantics is restricted to what is algorithmically computable from linguistic units, the resulting semantic representations will be so limited and impoverished relative to how expressions are actually understood that we would hardly recognize them as reasonable approximations to their meanings. [...] In short, the dictum that linguistic semantics is fully compositional does not rest on empirical observation, but is rather a matter of a priori definition by theorists who wish to consider language as a self-contained formal system. (1988: 17)

This caution explains why so few schemata are to be found in enunciative grammar books, which deal more with theory than with models. Models are deemed to be too abstract and they can hardly account for semantics. Theory and models are close, though they are not to be confused. Models present a high degree of abstraction, with a schematic structure. They are often represented with charts made up of arrows and boxes.

However, theory and models are close in that they are both supposed to generate testable hypotheses. Both theory and model/s imply the following stages:

$$
\text { observation / imagination / explanation / testing }
$$

The strength of a model is its abstractedness, its all-encompassing character but that is also its limitation: it is too general to be totally convincing to a linguist, in view of all the different language sorts and types in the world.

In spite of this, I would still retain two models, the one I presented earlier:

I (here / now) < (sentence schema)

Sentence schema: Argument-Source Connector (Argument-Target)

and the more complex one with boxes and arrows presented by psycholinguists. Both models take as their basis the human being as a speaker who produces language and as a thinking being, whose language is not cut off from cognitive schemata. 


\section{BIBLIOGRAPHY}

Benveniste, E. 1966. Problèmes de linguistique générale. Paris: Gallimard.

Benveniste, E. 1974. Problèmes de linguistique générale II. Paris: Gallimard.

Black, J. B. and G.H. Bower. 1980. “Story Understanding as Problem-Solving." Poetics 9, 223-250.

Cobley, P. (ed.). 2001. Semiotics and Linguistics. London: Routledge.

Comrie, B. 1989. Language Universals and Linguistic Typology. Oxford: Blackwell.

Damourette, J. and E. Pichon. 1952 [1911]. Des mots à la pensée. Essai de grammaire de la langue française. Paris: d'Artrey.

Denhière, G. 1984. Il était une fois... Compréhension et souvenirs de récits. Lille: Presses Universitaires de Lille.

Durand, J. 2001. "La transcription phonétique de l'anglais : problèmes théoriques et pratiques." In Rotgé, W. (ed.), Agrégation externe d'anglais, mode d'emploi. Paris: Ellipses.

Guéron, J. 1993. "La grammaire generative.” In Cotte, P. (ed.), Les Théories de la grammaire anglaise en France. Paris: Hachette.

Guillaume, G. 1988. Leçons de linguistique, vol. 8. Québec: Presses de l'Université de Laval.

Heine, B. 1997. Cognitive Foundations of Grammar. Oxford: Oxford University Press.

Jakobson, R. 1963. Essais de linguistique générale. Paris: Les Éditions de Minuit.

Langacker, R. 1988. “An overview of cognitive grammar.” In Rudzka-Ostyn, B. (ed.), Topics in

Cognitive Linguistics. Amsterdam: John Benjamins, 91-125.

Lapaire, J.-R. and W. Rotgé. 1998 [1991]. Linguistique et grammaire de l'anglais. Toulouse: Presses Universitaires du Mirail.

Lapaire, J.-R. and W. Rotgé. 1992. Réussir le commentaire grammatical de textes. Paris: Ellipses.

Lapaire, J.-R. and W. Rotgé. 1993. Séminaire pratique de linguistique anglaise. Toulouse: Presses Universitaires du Mirail.

Malavieille, M. and W. Rotgé. 1997. La grammaire anglaise coll. Bescherelle. Paris: Hatier.

O’ Grady, W., M. Dobrovolsky and F. Katamba. 1996. Contemporary Linguistics. London: Longman.

Roach, P. and J. Hartman (eds.). 1997. [Daniel Jones] English Pronouncing Dictionary. 15th edition.

Cambridge: Cambridge University Press.

Roulin, J.-L. (ed.). 1998. Psychologie clinique. Paris: Bréal.

Swan, M. 1995 [1980]. Practical English Usage. Oxford: Oxford University Press.

\section{NOTES}

1. Ce texte a fait l'objet d'une conférence plénière, prononcée lors du $23^{\mathrm{e}}$ Colloque du GERAS à l'ENS LSH, en mars 2002 sur le thème « Modèle-s ». 


\section{ABSTRACTS}

Although the term "model" is rarely used in linguistics, the notion of a model is central to many areas of linguistic inquiry. This paper demonstrates areas in which models are used, such as applied linguistics, phonetics and psycholinguistics. The author also contrasts the approach of generative grammarians, who are concerned with universals and have a weakness for models, with that of enunciative grammarians, who deal more with operations and how these translate into a given language, and are wary of models.

Bien que le terme "modèle" soit rarement employé en linguistique, la notion de modèle est essentielle à plusieurs domaines de recherche linguistique. Cet article décrit les domaines dans lesquels les modèles sont employés, tels la linguistique appliquée, la phonétique et la psycholinguistique. L'auteur compare également l'approche de la grammaire générative, qui traite d'universaux et a volontiers recours aux modèles, avec celle de la grammaire énonciative, qui traite plus d'opérations et de leur manifestation dans une langue donnée, et se méfie des modèles.

INDEX

Mots-clés: grammaire énonciative, grammaire générative, modèle, production de phrases

Keywords: enunciative grammar, generative grammar, model, sentence production

\section{AUTHOR}

\section{WILFRID ROTGÉ}

Wilfrid Rotgé est Professeur de linguistique anglaise à l'Université Paris X - Nanterre.

rotge@wanadoo.fr 